\title{
The Analysis of the Internet Development Based on the Complex Model of the Discursive Space ${ }^{+}$
}

\author{
Rafal Maciag \\ Institute of Culture, Jagiellonian University, 31-007 Kraków, Poland; rafal.maciag@uj.edu.pl; \\ Tel.: +48-602-2891-44 \\ + Presented at the IS4SI 2017 Summit DIGITALISATION FOR A SUSTAINABLE SOCIETY, Gothenburg, \\ Sweden, 12-16 June 2017.
}

Published: 9 June 2017

\begin{abstract}
This paper aims to present a new way of understanding and elaborating the current state of the reality which remains in the substantial dependency on the technology. An example of such a relatively mature technology is the internet. This paper shows the coherent descriptive schema of it based on the idea of discursive space which has two essential ingredients: complexity as a generic model and discourse as its direct substance. Abstract discursive space is created according to the idea of the physical state (phase) space. Discursive space lets further to describe the knowledge phenomenon.
\end{abstract}

Keywords: complexity; humanistic management; internet; discourse; knowledge; technology; Humanities

\section{Introduction: Internet and Technology as the Subject of the Description}

This paper aims to present a new way of understanding and elaborating the current state of the reality which remains in the substantial dependency on the technology. An example of such a relatively mature technology is the internet. This analysis allowed the creation of a coherent descriptive schema of this phenomenon in accordance with some observations made by the author [1,2]. The internet proved to be aptly chosen as an analysis field due to its maturity, the multiplicity of the identified forms, consequences, processes and phenomena, however, presented here method of analysis may be used also to other ubiquitous technologies. The main source of research perspective in this paper is the humanistic management. Very promising description mode provides the idea of complexity which is not new in the sense that it develops for many years, and also because there have been a number of attempts of using it within the social sciences, and even the Humanities e.g., [3-8].

\section{The Idea of Complexity as the Basis for the Construction of Discourse Space}

Understanding the internet in the context of complexity proposed here refers to the idea which appears primarily in the field of physics in accordance with its Greek formative base: physis (nature) [9] All entities actively present in the internet, such as organizations (all kinds of, existing in all areas and at all levels of social life) and individuals form a very large set. Hereby we have to deal with complex mutual interaction of these entities and groups, like in the other massive sets, such as e.g., gas molecules that make up the atmosphere, the environment of the development of the weather which is an emergent result of complex interactions of those molecules. Interaction in the case of the internet proceed in the discursive space, creating the reality of its functioning, which is equivalent to the configuration space, state space, phase space, etc. in the physical interpretation.

The space that appears in the case of the internet uses the idea of the abstract geometry of space and is described as a reality of language utterances, in which appears the notion or the idea of the 
internet. These utterances are conceptualized as a discourse in the sense defined by Michel Foucault $[10,11]$ as an emanation of knowledge. The discourse is so the construction allowing the transition from the experimental level to the theoretical and epistemological level. Experimental level is realized by different kinds of utterances about the internet or in connection with it occurring in the different kinds of science, media, business, politics, law and in the cultural discourses, different and most difficult to document: ethical, aesthetic, symbolic etc. Mentioned assemblages are the collective thematic prejudices of different nature and sources, and most importantly they are the result of a social practice, which means that every time they produce their own rules of validity, correctness, accuracy or veracity. They are also the articulation of the knowledge, which is local and rooted in the social and cultural processes, and on the other hand, it reflects the actual, historical state that changes over time. The variability of the prejudices (and the knowledge) is equivalent to the variability of the values of the dimensions in the physical interpretation. Per analogy the discourses can be consider as dimensions created in the space of discourses.

Such discourses could be articulated differently at the different points in time. Although it is difficult to parameterize them (but not excluded, since they are beings of language). Different articulation of the discourses can be understood as a different level of the intensity, the degree of impact, universality, nature of the prejudices etc. Entities actively present in the internet move in a space of real discourses in the way determined by the existence (articulation) of specific discourses, which can be understand as the presence of certain trends, developments, tendencies, etc., emerging over the level of the individual, pragmatic ways of individual entities, but collecting a lot of them and retaining effect on all others. This behavior remains in close correlation with the dynamics of knowledge represented in discourses. These trends and tendencies can be thought of as some general phenomena, present at the level of the internet as a whole. Because they change over time, and at any given time shall designate a state of the internet related to the real discourses, they can be treated as components of the complex trajectory arising in this way (or a collection of different trajectories). They are emergent, because they are nonlinear effect of the behaviors of individual entities, bringing a new quality, absent on their level.

\section{Description of the Basic Properties of Discourse Space}

In the physical interpretation the space of states, phase space, etc. is complete and thus make the system possible to describe. The dimensions of this space based on the mathematical parameters are a priori assumptions. In proposed way the discursive space which is an equivalent of the physical space exists as a result of the gradual uncovering and reconstruction of the most expressive elements of the trajectory of the internet in this space (that is, collect and organize expressions of discourses). Is thus in a way the opposite: discourses reveal a posteriori, as far as possible follow the development of the analysis of the phenomena at the time, although, of course, also require some preliminary findings, but very general.

Anticipating future system states becomes in this situation difficult. However, the composite image of the internet nature as a whole remains available, in which the emphasis is not just on the wholeness but complexity. This is a picture considering the opportunity of emergent phenomena e.g., the duration of the idea of freedom and openness on the internet the dominance of a new understanding of human subjectivity, the dominance of economizing and financialization of the world of human experience etc., and can be justified in this way. This is undoubtedly an incomplete interpretation from the point of view of its mathematical pattern, however, leading to a new, significant type of insight.

Discourses are certain social structures, based on the language. Language studies have gained extraordinary momentum and breadth in the twentieth century. This circumstance can be understand as an opportunity to extend of the idea of complexity of the area of symbolic representation of reality made mathematically into the different one which is the language, exhausting in this way the possible symbolizations and close opportunities of the description.

Discourses cannot be regarded as an ontological basis of reality, what takes a place in the case of the facts investigated and parameterized by physics. Discourses however are the constructions 
design to represent these facts, made within the societies. Therefore, they establish a type of medium between a certain, unreachable reality and man limited in his cognition to his own design, which is the language. Discourses in accordance with the pragmatics of the management are one of the parts of the environment in which the organizations exist. In accordance with the more advanced reasoning e.g., [12], discourses are also the main way knowledge exists.

\section{Knowledge as a Phenomenon that Can be Described Through Discursive Space}

Knowledge is extremely important cognitive category within management science e.g., [13,14]. Management refers to knowledge as a phenomenon which is the axis of the problems of the modern world, in which it performs the role of resource, forms the basis of the functioning of such entities as the organizations, enables them to expand, lets them locate itself in their environment, etc. so the knowledge is primarily treated instrumentally. However, the knowledge issue can also open the metatheoretical, analytical insight, in which appear the issues related to the status and meaning of science as such including management.

Knowledge as a phenomenon has also nature inherently problematic mainly because the dispute concerning its legitimacy, acquisition procedures, etc. still lasts what appears, for example, as a discussion on status of science. 20th century brings a fundamental re-evaluation of this status, which sources appear in mathematical structures of the 19th century [15]. They are stepping up especially in the second half of the 20th century, bringing the kind of upheaval that can be described as giving up hope in a transcendental status of knowledge and disclosure of the constructivist nature of it in which the language plays an essential role. This upheaval eventually lets to build also the idea of discourse. Management could be understood also in general and abstract terms, marking the beginning of the advanced, transdisciplinary type of reflection, referring to the epistemology. This kind of approach in full and self-conscious way develops within the so-called humanistic management. Humanistic management has a unique chance to combine a pragmatic and speculative (rhetorical) aspects, which allow to capture the fullness of knowledge issue.

Conflicts of Interest: The author declares no conflict of interest.

\section{References}

1. Maciąg, R.; Uniwersytetu Jagiellońskiego; Wydawnictwo. Pragmatyka Internetu: Web 2.0 jako środowisko; Wydawnictwo Uniwersytetu Jagiellońskiego: Kraków, Poland, 2013.

2. Maciąg, R.; Uniwersytet Jagielloński; Wydawnictwo. W Stronę Cywilizacji Internetu: Zarzadzanie w Naukach Humanistycznych; Wydawnictwo Uniwersytetu Jagiellońskiego: Kraków, Poland, 2016.

3. Byrne, D. Complexity Theory and the Social Sciences: An Introduction; Routledge: London, UK, 1998.

4. Byrne, D.; Callaghan, G. Complexity Theory and the Social Sciences: The state of the Art, 1st ed.; Routledge: New York, NY, USA, 2013.

5. Castellani, B.; Hafferty, F.W. Sociology and Complexity Science: A New Field of Inquiry; Softcover reprint of hardcover 1st ed. 2009 ed.; Springer: Berlin, Germany, 2010.

6. Cilliers, P.; Preiser, R. Complexity, Difference and Identity: An Ethical Perspective (Hardcover); Springer: Dordrecht, The Netherlands, 2010.

7. Jörg, T. New Thinking in Complexity for the Social Sciences and Humanities: A Generative, Transdisciplinary Approach, 2011 ed.; Springer: Dordrecht, The Netherlands, 2011.

8. Youngman, P.A.; Hadzikadic, M. Complexity and the Human Experience: Modeling Complexity in the Humanities and Social Sciences; Pan Stanford: Singapore, 2014.

9. Nolte, D.D. Introduction to Modern Dynamics: Chaos, Networks, Space and Time, 1st ed.; Oxford University Press: New York, NY, USA, 2015.

10. Foucault, M. L'archéologie du Savoir; Gallimard: Paris, France, 1969.

11. Foucault, M. L'ordre du Discours: Leçon Inaugurale au Collège de France Prononcée Le 2 Décembre 1970; Gallimard: Paris, France, 1971.

12. Lyotard, J.F. La Condition Postmoderne: Rapport sur Le Savoir; Éd. de Minuit: Paris, France, 1979.

13. Evans, C. Managing for Knowledge, 1st ed.; Routledge: London, UK, 2003. 
14. Jashapara, A. Knowledge Management: An Integrated Approach, 2nd ed.; Pearson Education Canada: Harlow, UK, 2010.

15. Maciag, R. W Strone Cywilizacji Internetu; Wydawnictwo Uniwersytetu Jagiellonskiego: Kraków, Poland, 2016.

(C) 2017 by the authors. Licensee MDPI, Basel, Switzerland. This article is an open access article distributed under the terms and conditions of the Creative Commons Attribution (CC BY) license (http://creativecommons.org/licenses/by/4.0/). 